$17^{\text {th }}$ International Congress of Metrology, 08008 (2015)

DOI: $10.1051 /$ metrology / 201508008

(C) Owned by the authors, published by EDP Sciences, 2015

\title{
Moisture measurement setup for wood based materials and biomasses
}

\author{
Ojanen-Saloranta $\mathrm{M}^{1}$, Sairanen $\mathrm{H}^{1}$, Salminen $\mathrm{J}^{1}$, Kajastie $\mathrm{H}^{1}$ and Heinonen $\mathrm{M}^{1, a}$ \\ ${ }^{1}$ Centre for Metrology MIKES, VTT Technical Research Centre of Finland Ltd, P.O. Box 1000, FI-02044 VTT, Finland
}

\begin{abstract}
Résumé. Dans la plupart des applications de mesure de l'humidité, perte à la desiccation est considerée comme la référence la plus fondamentale. Quand on desséche un échantillon au materiel solid, la perte de masse ne depend seulemet de teneur de l'eau, mais le degré de l'engagement physique et chimique de l'eau, et le teneur des matériaux volatiles non-aqueux dans l'échantillon. Pour developper une système non-ambigue pour mésurer de teneur de l'eau aux matériaux en bois, Centre for Metrology MIKES en Finlande a dévéloppé un nouveau étalon primaire en cadre de projet EMRP METefnet. Pour que l'appareil soit specifique pour l'eau sans perdre le lien avec les détérminations de l'humidité avec perte à la desiccation traditionelle, l'étalon primaire s'inclut un piège de l'eau pour l'eau évaporé pendant la desiccation à l'addition de détérmination de la perte de masse totale. Cet article donne un résumé de la méthode et l'appareil pour les échantillons de $50 \mathrm{~g}$ à $400 \mathrm{~g}$, et présente une méthode pour baisser la masse d'échantillon jusqu'au quelques grams. L'estimate de l'incertitude relative élargie est moins que $2 \%$.
\end{abstract}

\section{Introduction}

When determining moisture in wood based materials, reference measurements are carried out using an ovendrying method [1-3]. This and other Loss-on-Drying methods (LoD) are recognized today as the most reliable basis for quality insurance in moisture measurements of a wide range of solid materials. However, LoD is an ambiguous method because the measured mass loss depends not only on the water content, but also on the content of non-aqueous volatile components in the sample [4,5]. For example, pitchy wood used as biofuels may contain significant amount of non-aqueous components that contribute to the moisture value determined with LoD but, opposite to water, have a high calorific value [5].

To overcome this problem, a concept of combining LoD with cold-trap-based water detection was introduced by the authors in [6]. Applying this concept moisture analysis results are simultaneously obtained in terms of the conventional moisture content (in accordance to current documentary standards) and the water mass fraction (defined as the mass of removed water divided by the mass of the sample before drying). A system has been developed at MIKES (Centre for Metrology MIKES, VTT Technical Research Centre of Finland Ltd) for measuring biomass and other wood-based material

\footnotetext{
${ }^{\bar{a}}$ Corresponding author: martti.heinonen@vtt.fi
}

samples up to $400 \mathrm{~g}$. It's applicability to small samples, however, is limited due to a large sample container and the construction of the cold trap. Therefore, a smaller sample cell and a desiccant type water trap were designed to enable measurements of other types of materials, e.g. paper and powders.

A description of the system for samples of $50 \mathrm{~g}$ to $400 \mathrm{~g}$ is presented with an uncertainty analysis in this paper. Also, a technical concept for extending the sample size range down to a level of few grams is introduced here. The research is carried out within the joint European metrology project "METefnet - Metrology for Moisture in Materials" [7] that is developing unambiguous but feasible methods for establishing and disseminating SI traceability in measurements of moisture in solids.

\section{Principle of operation}

The moisture measurement set-up was constructed at MIKES as a closed air circulation loop. Air is pumped through a heat exchanger to a sample container. The air mixed with water vapour from the sample flows through a humidity sensor to a water trap and back to the pump.

By heating the heat exchanger and the sample container in an oven, the sample is dried according to the procedure described in the relevant LoD standards [1-3]. 
The sample container is weighed before and after drying with a separate electrical balance. After placing a sample, the container lid is closed and not opened until the complete measurement procedure ends. During the weighings also the tube connections of the container are closed. The drying process is monitored with a capacitive humidity sensor. The temperature of the sensor and the tubing from the oven to the water trap are maintained at a temperature sufficiently high to avoid condensation at any point of the drying process.

The conventional moisture content is determined from the apparent mass loss of the sample container during drying. The water mass fraction is determined by dividing the apparent mass increase of the water trap during drying the sample with the original sample mass in the container. If there are no non-aqueous volatiles in the sample the determined mass changes of the sample container and the water trap are equal. In practice, full water selectivity is not achieved with a water trap when measuring e.g. wood samples with a significant volatile organic compound (VOC) content. However, this can be evaluated and taken into account by analysing the trapped water.

Also, the on-line monitoring of the air humidity at the sample container exit provides a possibility to determine the moisture of the sample: If the air flow rate is known, the amount of water removed from the sample can be calculated by integrating the humidity sensor reading over the complete measurement time. However, the achievable accuracy is highly limited by the characteristics of the sensor. The uncertainty of the flow rate is another significant limiting factor when applying this approach.

\section{Measurement system}

\subsection{Set-up for samples up to $400 \mathrm{~g}$}

Figure 1 shows the set-up constructed at MIKES for measuring moisture and water content of solid samples up to $400 \mathrm{~g}$.

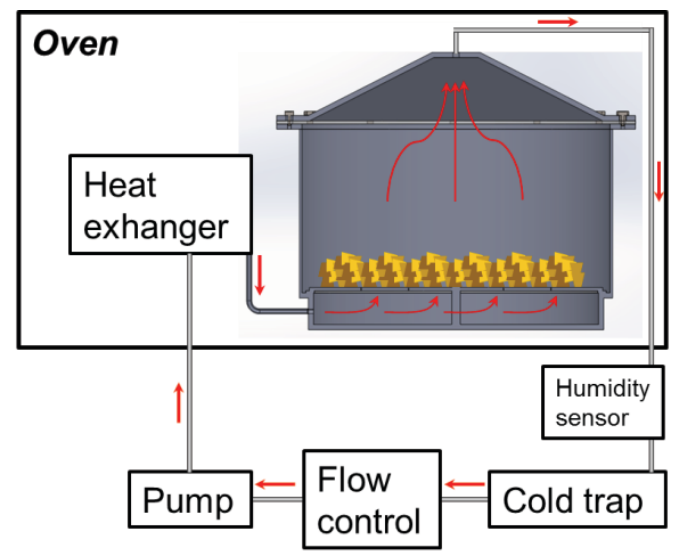

Figure 1. Measurement set-up for samples up to $400 \mathrm{~g}$. Red arrows show the air circulation in the system.

In this set-up, the sample is placed in the container on a mesh plate. Air enters the container below the plate, flows through the plate and the sample (see red arrows in the container of Figure 1) and exits through an outlet on the top. The temperature of the sample is monitored with a Pt100 sensor placed in the container vertically so that its lower end is in the sample (not shown in the figure). Another Pt-100 sensor is place in the oven close to the sample container to monitor the oven temperature. The sample container is connected to the heat exchanger and the outlet tube with quick couplings equipped with closing valves enabling efficient operation. The outer diameter of the stainless steel container is $350 \mathrm{~mm}$ and the height is $300 \mathrm{~mm}$, and its mass is about $9 \mathrm{~kg}$.

The evaporated water is removed from the air circulation in this setup by condensing it in a cold trap. The trap consists of two cylinders fully immersed in a liquid bath. The bath temperature is set to $+5^{\circ} \mathrm{C}$, which is close enough to the ambient dew-point temperature to minimise the background effect (i.e. effect of water vapour in air when closing the sample into the container) and to perform conventional LoD measurements in compliance with the relevant documentary standards.

Both the sample container and the cold trap are weighed using a balance with the capacity of $10.2 \mathrm{~kg}$ and the scale interval of $0.01 \mathrm{~g}$.

\subsection{Set-up for samples $5 \mathrm{~g}$ to $50 \mathrm{~g}$}

Due to the large size of the sample container and the construction of the cold trap, the described set-up is hardly applicable to measurements of small and relatively dry samples, e.g. paper and powders. To overcome this limitation, a smaller sample container was designed and constructed. Furthermore, applying the same design a desiccant dryer was constructed to be used as the water trap instead of the cold trap. In this way the small amount of water to be evaporated from the sample can be determined more accurately.

A drawing of the small sample container is shown in Figure 2. The container was developed from a Vaisala HMK15 calibration chamber by introducing an inlet tube through the bottom and an outlet tube through the transit cover. The ends of the both tubes in the chamber are covered with a sintered filter. The container is connected to the heat exchanger and the outlet tube with quick couplings enabling equipped with closing valves efficient operation.

The outer diameter of the anodised aluminium container is $60 \mathrm{~mm}$ and the height is $51 \mathrm{~mm}$, and its mass with the couplings is about $400 \mathrm{~g}$.

The desiccant dryer-based water trap consists of one or two desiccant containers with the same design as the small sample container. The efficiency of the trap depends on the absorbing material and the flow rate. The absorption of non-aqueous volatiles is studied by comparing different absorption materials.

Both the sample container and the desiccant dryer are weighed using a balance with the capacity of $5.1 \mathrm{~kg}$ and the scale interval of $1 \mathrm{mg}$.

The same oven and air circulation system are used with both sample containers and water traps. 


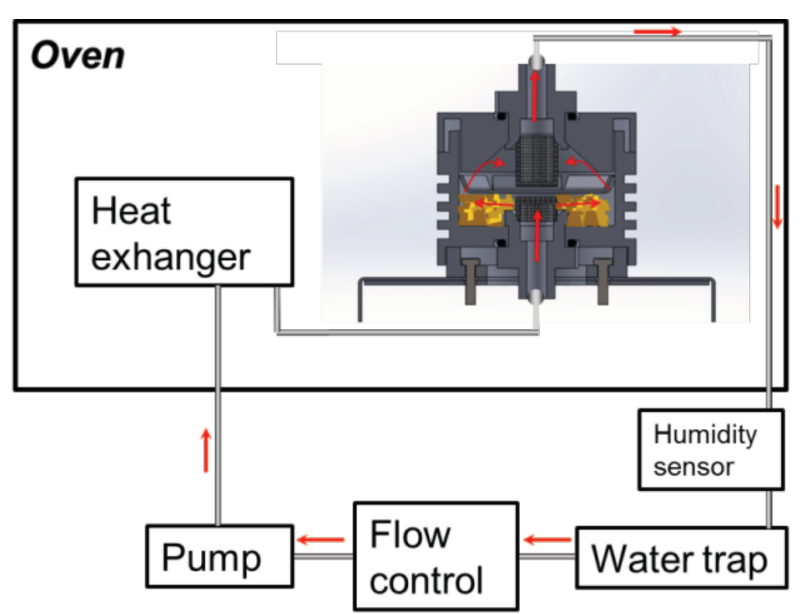

Figure 2. Measurement set-up for samples of $5 \mathrm{~g}$ to $50 \mathrm{~g}$. The water trap may be either a cold trap or a desiccant dryer. Red arrows show the air circulation in the system.

\section{Measurement uncertainty}

The water content of a sample $(w)$, i.e. water mass fraction expressed in percent, is calculated as:

$$
w=\left[\frac{\Delta m_{m}+\delta_{t r}+\delta_{v}}{m_{0}+\delta_{B}}\right] \times 100 \% \mathrm{~W}
$$

where

$m_{0}=$ initial mass of the sample

$\Delta m_{m}=$ mass increase of the trap

$\delta_{t r}=$ correction due to non-ideal trapping efficiency for water vapour

$\delta_{v}=$ correction due to trapped non-aqueous volatiles

$\delta_{B}=$ correction due to non-ideal characteristics of the balance (calibration, non-linearity, hysteresis, thermal effects etc.)

Estimates of the corrections $\delta_{t r}, \delta_{v}$ and $\delta_{B}$ are zero but they contribute to the measurement uncertainty. The initial mass and the mass increase of the cold trap contribute to both estimate and uncertainty. A summary of an uncertainty analysis for a biomass sample of $200 \mathrm{~g}$ is given as an example in Table 1. Here we assumed that only water contributed to the mass increase of the cold trap.

Table 1. Uncertainty analysis for a biomass sample of $200 \mathrm{~g}$ with water content of $50 \% \mathrm{w}$.

\begin{tabular}{|l|c|c|c|c|}
\hline \multicolumn{1}{|c|}{$\begin{array}{l}\text { Uncertainty } \\
\text { component }\end{array}$} & Estimate & $\begin{array}{c}\text { Standard } \\
\text { uncertainty } \\
(\mathbf{g})\end{array}$ & $\begin{array}{c}\text { Sensitivity } \\
\text { coefficient } \\
(\%) w / g)\end{array}$ & $\begin{array}{c}\text { Contribution to } \\
\text { combined unc. } \\
(\%)\end{array}$ \\
\hline $\begin{array}{l}\text { Initial mass of } \\
\text { sample }\end{array}$ & 200 & 0.05 & 0.25 & 0.013 \\
$\begin{array}{l}\text { Mass of evaporated } \\
\text { water }\end{array}$ & 100 & 0.02 & 0.5 & 0.010 \\
\hline $\begin{array}{l}\text { Balance } \\
\text { Trap efficiency }\end{array}$ & 0 & 0.01 & 0.25 & 0.003 \\
\hline $\begin{array}{l}\text { Trapped non- } \\
\text { aquous volatiles }\end{array}$ & 0 & 0.1 & 0.5 & 0.050 \\
\hline \multicolumn{4}{|c|}{ Combined standard uncertainty } & 0.053 \\
\hline \multicolumn{4}{|c|}{ Expanded uncertainty $(k=2)$} & 0.11 \\
\hline
\end{tabular}

Uncertainty estimations for different moisture levels show that the expanded relative uncertainty of the moisture analysis is less than $2 \%$.

\section{Discussion}

The system has been tested with many types of wooden samples (wood chips, sawdust, wood pellets) covering different sample and particle sizes. A detailed analysis of these tests will be published in near future.

R. Samuelson et al. concluded in [5] that during biomass drying the level of VOC emission is $0.1 \%$ to $11 \%$. With a few samples measured in the MIKES set-up the VOC emission was high enough to contaminate the cold trap. To take into account the amount of trapped VOCs in a more comprehensive way, we are developing a practical approach for analysing a water sample from the cold trap.

Measurements with samples containing low level of non-aqueous volatiles have shown a good agreement with the traditional LoD determination. In future, interlaboratory comparisons will be carried out to provide information about the equivalence of different types of primary moisture determinations.

\section{Conclusion}

MIKES has set up a new type of LoD primary standard to provide an unambiguous realisation for water mass fraction in wood-based materials. To include water specificity without losing a link to the traditional LoD moisture determinations, the primary standard comprises the overall mass loss determination and measurement of evaporated water using a water trap. The water evaporation is also monitored with a capacitive humidity sensor. The developed set-up was found applicable to samples of $50 \mathrm{~g}$ to $400 \mathrm{~g}$. To extend the application range to smaller samples, e.g. paper and powder, another sample container and water trap were designed. With these, samples of few grams can be measured with an appropriate uncertainty. The estimated relative expanded uncertainty is less than $2 \%$.

\section{Acknowledgements}

This work was carried out within the SIB64 METefnet project funded by the European Metrology Research Programme (EMRP) that is jointly funded by the EMRP participating countries within EURAMET and the European Union. 


\section{References}

1. CEN, "Solid biofuels - Determination of moisture content - Oven dry method - Part 1: Total moisture Reference method," EN 14774-1, 2009.

2. ISO, "Wood - Determination of moisture content for physical and mechanical tests," ISO 3130, 1975

3. ASTM, "Standard Test Methods for Direct Moisture Content Measurement of Wood and Wood-Base Materials," ASTM D4442, 2007

4. R. Samuelsson, J. Burvall, and R. Jirjis, "Comparison of different methods for the determination of moisture content in biomass," Biomass Bioenerg., vol. 30, no. 11, pp. 929-934, 2006

5. R. Samuelsson, C. Nilsson, and J. Burvall, "Sampling and GC-MS as a method for analysis of volatile organic compounds (VOC) emitted during oven drying of biomass materials," Biomass Bioenerg., vol. 30, no. 11, pp. 923-928, 2006

6. M. Ojanen, H. Sairanen, K. Riski, H. Kajastie, M. Heinonen, Moisture measurement setup for wood based materials, NCSLI Measure J. Meas. Sci., 9 (2014), No. 4, pp. 56-60

7. EURAMET, "Metrology for Moisture in Materials," Summary for JRP SIB64 METefnet, 3 p., 2013, and www.metef.net 